\title{
LA INTERROGACIÓN EN INFINITIVO COMO RÉPLICA
}

María Victoria Escandell Vidal

$U N E D$

\section{INTRODUCCIÓN}

Cuando se habla de la interrogación directa y de los problemas gramaticales que puede plantear su estudio, suele pensarse en cuestiones tales como la presencia o ausencia en la oración de determinadas palabras interrogativas, la existencia de un patrón entonativo característico, o la posición que deben ocupar los diferentes elementos de acuerdo con la función sintáctica que desempeñen; y todo ello suele entenderse siempre referido a oraciones en cuyo predicado interviene una de las llamadas formas personales ${ }^{1}$ del verbo (es decir, aquellas que presentan morfemas de tiempo-modo y persona), ya que se admite generalmente que las formas no personales (infinitivo, gerundio y participio) deben, en cierto modo, «depender" de otro verbo ${ }^{2}$.

1 Utilizo aquí la denominación propuesta por la Real Academia Española en su Esbozo de una nueva gramática de la lengua española, Madrid, Espasa-Calpe, 1973 \$.16, pero hay muchas otras, que recoge pormenorizadamente E. Luna Traill: Sintaxis de los verboides en el habla culta de la ciudad de México, México, U.N.A.M., 1980 (pp. 17 y ss).

2 «Depender» está aquí usado en un sentido informal, pero que responde bastante bien a la idea tradicional sobre el tipo de funciones que la gramática asigna a las formas no personales del verbo. Véase a este respecto lo dicho por la R.A.E.: Esbozo... 3.16.1 (he subrayado las expresiones más significativas de este parecer):

«Además de ser formas no personales, [infinitivo, gerundio y participio] tienen en común el no expresar por sí mismas el tiempo en que ocurre la acción, el cual se deduce del verbo de la oración en que se hallen, de los 
Existe, sin embargo, una serie de oraciones en las que el núcleo del predicado verbal es una forma no personal, sin que haya en ellas ningún verbo en forma personal del que aquélla pudiera «depender» ${ }^{3}$. Vamos a centrarnos ahora en los infinitivos independientes. Veamos algunos ejemplos:

1) a - No, no, ¿delante de ella predicar? ¿Yo? ¿Darles consejos? (Unamuno)

b - Pero, ¿cómo explicarle el que la antigua criada se sentara a la mesa a comer con los de casa? (Unamuno)

c - Pero, casarme con "ese hombre» sólo porque es rico... (Concha Espina)

d - Seguir trabajando, y con vuestro esfuerzo aumentaréis vuestro nivel de vida (Delibes)

e - Venían sofocados. Correr a un lado, correr al otro... ${ }^{4}$

adverbios que los acompañen y de otras circunstancias de la elocución. (...) En las oraciones compuestas, los tres pueden construirse como elementos sintácticos incorporados a una oración subordinada (construcción conjunta), o pueden adquirir cierta independencia oracional, equivalente a una subordinada circunstancial (construcción absoluta).*

${ }^{3}$ El carácter independiente del infinitivo en estos casos no es algo comúnmente aceptado por todos los estudiosos. Pueden verse las opiniones de varios autores recogidas y comentadas por S. Skydsgaard: La combinatoria sintáctica del infinitivo español (2 vol.), Madrid, Castalia, 1977 (especialmente pp. 1.125 y ss.). Está bastante extendida la idea de que tales construcciones en realidad han sufrido un proceso de elipsis, quedando así salvaguardada la condición *dependiente* o usubordinada* del infinitivo. M. L. Hernanz Carbo: El infinitivo en español, Bellaterra, Publicaciones de la Univ. Autónoma de Barcelona, 1982 (cap. 4), desde su perspectiva de análisis generativista, también propone la solución de la elipsis, diciendo, en este caso, que se trataba de un verbo abstracto del que dependia el infinitivo. Pero, dado que parece difficil controlar adecuadamente tanto la naturaleza sintáctico-semántica como las posibilidades de recuperación del verbo elidido, los inconvenientes de esta propuesta parecen superiores a sus ventajas. La gramática debe poder generar libremente todo este tipo de secuencias, y será luego una serie de condiciones pragmáticas - sobre ellas volveré más adelante- la que dará cuenta de su uso apropiado en unas situaciones discursivas determinadas.

Skydsgaard ( $O_{p}$. cit...), sin embargo, concluye que

$$
\begin{aligned}
& \text { (p. 1.. el infinitivo está independizado por una entonación especial» }
\end{aligned}
$$

a la que denomina $\rightarrow$ no con demasiada fortuna, a mi juicio- entonación de elipsis, y que «cubre el terreno de las entonaciones interrogativa, volitiva y emocionals (p. 1.125).

La entonación tiene, efectivamente - como trataré de demostrar- un papel fundamental en la aceptabilidad de estas estructuras.

Los ejemplos los he tomado de Hernanz Carb6, Op. cit., pp.369-370; alli aparece la localización completa de las citas de cada uno de los autores mencionados. 
Las oraciones 1)a y 1)b muestran dos tipos diferentes de construcciones interrogativas; 1)c, 1)d, y 1)e son ejemplos de lo que Hernanz Carbo ${ }^{5}$ llama infinitivo exclamativo, infinitivo imperativo e infinitivo narrativo, respectivamente $^{6}$.

La perspectiva de análisis adoptada en los trabajos más conocidos ${ }^{7}$ es la que se sitúa en el terreno del infinitivo. La construcción interrogativa es, entonces, una más de las posibles estructuras independientes, que, a su vez, no constituyen sino una pequeñísima parte de la sintaxis del infinitivo. La consecuencia es que el estudio de estas oraciones queda, en ocasiones, reducido a la simple mención de su existencia y a su ilustración con algunos ejemplos. Pero, incluso en el mejor de los casos, los resultados de estos análisis no dejan de parecer desalentadores, si se atiende a la conclución de Hernanz Carbó:

«En suma, las interrogativas infinitivas no constituyen un grupo homogéneo de enunciados, sino más bien una clase de oraciones sometidas en mayor o menor grado a las influencias contextuales y que comparten, aparte de la entonación, la propiedad de hallarse regidas en la estructura profunda por un predicado abstracto o real que se elide posteriormente, una vez efectuada la infinitivización o la inserción de /que $/ 4$. y 1)b:

Sigamos observando algunas oraciones semejantes a las de 1)a

2) a - ¿Dejarle yo en la estacada?

b - ¿Pedro venir a la fiesta?

c - ¿Ver a quién?

d - ¿Por qué no ir al cine?

e - ¿Cuándo encontrarle en casa?

La primera impresión que pueden producir algunas de estas secuencias es la de que se trata de oraciones dudosamente gramaticales: ello

\footnotetext{
5 Hernanz Carb6, Op. cit., p. 369.

- No es mi intención entrar aquí en una polémica terminológica, pero me parece que estas denominaciones son más que discutibles: responden a criterios pragmáticos, de uso de enunciados concretos, y no $\rightarrow$ como sería de esperar, dado el tipo de metodología empleada por esta autora - a una caracterización formal de la oración que contiene a los infinitivos; puede servir, sin embargo, como designación intuitiva. La relación tampoco es completa: habria que añadirle los otros casos que estudia Skydsgaard, Op. cit., pp. 1.125 y ss.

7 Piénsese en los ya citados de Skydsgaard, Luna Traill, Hernanz Carb6.

8 Hernanz Carbo, Op. cit., p.387.
} 
ocurre especialmente con 2)c, parcialmente con 2) $a$ y 2) $b$, pero no con 2)d y 2)e. Sin embargo, en cuanto pensemos que se trata de enunciados inmersos en un contexto, resultan perfectamente adecuados e interpretables:

3) A: - Andrés está enfadado contigo. Dice que no entiende cómo precisamente tú no quisiste ayudarle y le dejaste en la estacada.

B: - ¿Dejarle yo en la estacada? Ni hablar

4) A: - Pedro dijo que vendría a la fiesta

B: - ¿Pedro venir a la fiesta? Ni lo sueñes: odia las fiestas

5) A: - ¿La has visto hoy?

B: - ¿Ver a quién?

6) A: - No creo que debamos quedarnos aquí. ¿Por qué no ir al cine? La película parece divertida

7) A: - Me gustaría decírselo pronto, pero ¿cuándo encontrarle en casa? Ya sabes que está siempre de viaje, y no hay manera de dar con él.

La inclusión en unas situaciones de discurso adecuadas de las estructuras que venimos considerando, además de demostrar la adecuación de las oraciones 2)a-e, pone de manifiesto ciertos comportamientos que nos permiten trazar una distinción de la mayor importancia.

En efecto, los ejemplos 3) y 4) corresponden a aquel tipo de construcción interrogativa ${ }^{9}$ que solemos conocer con el nombre de interrogación general y que se caracteriza por no llevar ninguna de las palabras interrogativas ${ }^{10}$ (adjetivos, pronombres $y$ adverbios) en posición

${ }^{9}$ Pueden verse más detalles sobre la tipología de las oraciones interrogativas en M. V. Escandell Vidal, Introducción al estudio de las estructuras interrogativas, Memoria de Licenciatura. Madrid, 1981. Alli hallará el lector una justificación razonada, basada en criterios puramente sintácticos, de la necesidad de considerar como interrogaciones generales a aquellas que no llevan palabra interrogativa en posición preverbal.

10 En mi tesis doctoral La interrogación en español: Semántica y Pragmática, Madrid, 1986, aparecen presentados los principales argumentos a favor de una consideración de 
preverbal; según esta definición, también debemos incluir en esta categoría a la oración ejemplificada en 5): en todos estos casos la construcción analizada aparece como réplica de un hablante con respecto a un enunciado precedente de su interlocutor.

La interrogación parcial -la que lleva una palabra interrogativa en posición preverbal- queda ejemplificada en 6) y 7), que, al contrario de lo que ocurría en los casos anteriores, no necesitan ser réplica a un discurso de otro emisor.

Parece, por tanto, razonable analizar de manera separada la interrogación general y la parcial, puesto que estas dos construcciones muestran diferencias tanto formales (la presencia o ausencia de palabras interrogativas en posición preverbal), como distribucionales (la necesidad de un enunciado precedente emitido por otro hablante), $y$, por supuesto, pragmáticas.

Las páginas que siguen están dedicadas al estudio de la interrogación directa " con infinitivo, dando entrada al punto de vista opuesto, esto es, al relativo a la interrogación. Estudiaré estructuras como las ejemplificadas en $($ ) $a-b)$ y 2), analizando sus características formales, sus particularidades sintácticas y los diversos usos pragmáticos que de ellas puede hacerse cuando constituyen enunciados; y todo ello, tomando en consideración el carácter esencialmente interrogativo de tal construcción ${ }^{12}$.

los tradicionalmente llamados adjetivos, pronombres y adverbios interrogativos dentro de una única categoría definida por unos rasgos comunes.

${ }^{11}$ No constituyen objeto de este estudio, por tanto, las interrogaciones indirectas con infinitivo como

Juan no sabía por dónde salir

puesto que este fenómeno se relaciona con otros tipos de subordinación, como demuestran los siguientes ejemplos

Pedro lamentaba ser tan tímido

Luis buscaba una chica con la que bailar

El infinitivo es, en estos casos, «dependiente», ya que su sujeto debe ser correferencial con el del verbo principal. Resultan, pues, agramaticales las secuencias que no cumplen este requisito

* Juan no sabía por dónde salir Andrés

- Pedro lamentaba ser tan tímido tú

* Luis buscaba una chica con la que bailar su primo

Esta regla no tenía igual alcance en la lengua antigua, en la que era posible una oración como

Esto me demuestra ser tú mi señora Melibea (Celestina).

12 No me ocuparé, por tanto, del posible origen derivacional del infinitivo, que es materia abordada por otros autores. Sí trataré, en cambio, de las restricciones - tanto sintácticas como pragmáticas- que impone la presencia del infinitivo. 


\section{Características Formales}

\subsection{La entonación}

Como es sabido, la construcción interrogativa general se caracteriza desde el punto de vista gramatical por llevar indisociablemente un patrón entonativo / $1212 \uparrow /$ cuyo rasgo más destacable es su tonema final ascendente ${ }^{13}$, y que se opone al esquema prosódico declarativo / $1211 \downarrow /$. Sería de esperar, por tanto, que la interrogación general con infinitivo se ajustara al patrón arriba descrito. Sin embargo, pruébese a leer los ejemplos 3), 4) y 5) con un esquema /1 $212 \uparrow$ / para la interrogación infinitiva: los diálogos parecen perder su cohesión, sencillamente porque la entonación no resulta adecuada. Pero tampoco puede, evidentemente, sustituirse por el esquema entonativo caracteristico de las declarativas. ¿Qué solución buscar?

En otro lugar ${ }^{14}$ he propuesto que la interrogación general posee otro patrón prosódico distintivo y funcional, aproximadamente $12232 \uparrow$ /, que sirve para diferenciar, por un lado, la negación externa de la negación interna en las oraciones interrogativas; $y$, por otro, la interrogación orientada - aquella en la que el emisor no es neutral con respecto al contenido proposicional expresado- de la que no lo es. Cualquier sustitución de uno de estos patrones por el otro trae aparejado un cambio radical en la interpretación de la secuencia. Pues bien, el esquema que conviene a la interrogación general con infinitivo no es $/ 1212 \uparrow /$, sino $12232 \uparrow /$ :

3) A:- Andrés está enfadado contigo. Dice que no entiende cómo precisamente tú no quisiste ayudarle y le dejaste en la estacada.

B:- ¿Dejarle yo en la estacada? Ni hablar. \#/ $121212 \uparrow$ I

$12232 \uparrow /$

4) A:- Pedro dijo que vendría a la fiesta

B:- ¿Pedro venir a la fiesta? Ni lo sueñes: odia las fiestas \#/ $12212 \uparrow$ /

$12232 \uparrow /$

13 Vease especialmente el último capítulo de A. Quilis, Fonética acústica de la lengua española, Madrid, Gredos, 1981.

14 Escandell Vidal, La interrogación..., caps. 7 y 12. 
Más adelante propondré una interpretación sobre este hecho. Antes hay que considerar el ejemplo 5), que parece resistirse a aceptar cualquiera de los dos esquemas de la interrogación general; y, sin embargo, lo único que admite es el esquema prosódico declarativo $/ 1211 \downarrow \downarrow$ /:

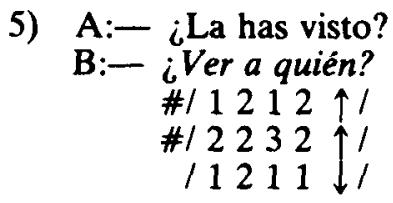

Recuérdese que éste era, precisamente, el que caracterizaba también a las interrogaciones parciales, y su aparición debe relacionarse con el carácter de pregunta relativa que tiene este ejemplo.

El diálogo 5) no debe confundirse con el reflejado en 8):

8) A:- ¿Has ido a ver a Juan?

B:- ¿Ver a quién? Ni soñarlo, yo con ése no hablo más.

En efecto, este último presenta una situación discursiva completamente diferente a la de 5), aunque en ambos casos el emisor $B$ inicie su enunciado con la misma estructura sintáctica. En 5) la interrogación es una verdadera pregunta por medio de la cual el hablante $B$ pretende averiguar la referencia exacta de ese la empleado por su interloculor; en 8), en cambio, $B$ no pretende obtener una información, sino que su enunciado se comporta de forma similar a la de los ejemplos 3) y 4); y la palabra interrogativa no responde a un desconocimiento, como pone de relieve la anáfora definida y deíctica ése, referida al mismo individuo que a quién, imposible en un diálogo como el de 5) sin que se modificara todo el conjunto de presuposiciones asociadas. Nuevamente, queda demostrado que la entonación tiene una auténtica función distintiva, que determina automáticamente la selección de una de las interpretaciones y el rechazo de la otra. 


\subsection{El Sujeto del Infinitivo}

Una oración como

9) ¿Decírselo ahora?

presenta al infinitivo sin ningún sujeto expresado. Fuera de contexto, no puede recuperarse. Pero hemos dicho que las interrogaciones generales no se admiten como iniciadoras de diálogo, sino que son necesariamente réplicas a un enunciado previo. Pues bien, es precisamente en ese enunciado precedente en el que puede recuperarse contextualmente el sujeto:

10) A:- Díselo ahora

B:- ¿Decírselo [yo] ahora?

11) A:- Se lo voy a decir ahora

B:- ¿Decírselo [tú] ahora?

12) A:- Van a ir a decírselo ahora

B:- ¿Decírselo [ellos] ahora?

Además de esta asignación contextual (que funciona también en los casos de infinitivos dependientes), los ejemplos 2) $a$ y 2) $b$ ponen también de relieve otra de las características sintácticas de este tipo de construcciones: me refiero a la posibilidad de aparición de un sintagma nominal en función de sujeto ${ }^{15}$.

2) a: - ¿Dejarle yo en la estacada?

b:- ¿Pedro venir a la fiesta?

13) a:- ¿Asustarme yo por tan poca cosa? ¿Qué va!

b:- ¿Mentir $t u ́ ?$ ¿Y tus principios morales?

c:- ¿Luis engañarte? No lo creo.

15 Puede aparecer también, por supuesto, cualquiera de los otros complementos. 
Al carecer el infinitivo de los morfemas de concordancia de número y persona, que sí poseen las formas flexivas, la función de sujeto queda en estos casos definida exclusivamente por la ausencia en el sintagma de marcas preposicionales ${ }^{16}$.

Lo interesante es destacar que la aparición de este sintagma en función de sujeto es libre, y no "dependiente» como ocurre en las formas de infinitivo subordinado ${ }^{17}$; de tal modo que este hecho puede constituir un argumento más a favor de la idea de que los infinitivos independientes son realmente autónomos, y no están subordinados a ningún tipo de predicado abstracto de elisión obligatoria, como propone, entre otros, Hernanz Carbó.

En estas construcciones es «libre» ${ }^{18}$ incluso la posición del sujeto con respecto al infinitivo, como ponen de manifiesto los ejemplos 2) $a-b$ y 13) a-c. En efecto, las interrogaciones con infinitivo tienen un comportamiento singular, puesto que la posposición del sujeto sí parece obligatoria en las otras construcciones que lo admiten:

14) a:- Al acabar la clase, salimos del aula

b:- * Al la clase acabar, salimos del aula

15) a:- El quererlo tú no es razón suficiente

b:- ${ }^{*}$ El tú quererlo no es razón suficiente ${ }^{19}$

${ }^{16}$ Me refiero al hecho de que esta función no puede ser desempeñada ni por un sintagma precedido de preposición ni por ninguna de las formas pronominales que contienen información preposicional y que se usan para realizar las funciones de objeto directo $e$ indirecto.

17 Véanse de nuevo los ejemplos de la nota $11, y$ lo dicho con respecto a aquel tipo de estructuras por Skydsgaard, $O p$, cit., especialmente pp.1.106 y ss. Las oraciones tradicionalmente llamadas adverbiales o circunstanciales no quedan incluidas en la idea de «subordinación», como hacen notar, entre otros, la R.A.E.: Esbozo... 3.16.1. y Hernanz Carbó: Op. cit., p.351:

"... dividiremos las proposiciones infinitivas en dos grandes grupos: a) proposiciones infinitivas fuera del ámbito de la rección del verbo principal; b) proposiciones infinitivas que entran dentro de la rección del verbo principal. Las primeras pueden llevar libremente sujeto, las segundas, no.

Dentro del primer grupo cabe integrar las subordinadas adverbiales y también los infinitivos exclamativos, interrogativos y narrativos. Las subordinadas adverbiales se diferencian de las completivas en que mantienen una relación mucho más laxa con la principal que estas últimas. En otras palabras, no van "regidas" por el verbo dominante..."

18 «Libre» quiere decir aquí que obedece al mismo tipo de constricciones que el sujeto léxico de una forma personal.

19 Algunos informantes no consideran agramatical este último ejemplo, aunque prefieren 15)a, mientras rechazan de plano 14)b. Tal vez el carácter humano del agente podría explicar la aparente asimetría entre los ejemplos (4)a-b y estos otros: 


\subsection{Réplicas en infinitivo y réplicas nominales}

Finalmente debemos considerar la existencia de una aparente anomalía en las réplicas que copian una parte del enunciado anterior. Obsérvese el siguiente ejemplo:

16) A:- Luis ha sabido solucionarlo porque él es listo

B:- ${ }^{*}$ ¿Ser listo Luis?

¿Luis ser listo?

¿Listo Luis?

¿Luis listo?

El emisor $B$ no puede reproducir el verbo ser que utilizaba su interlocutor porque la oración resulta agramatical; pero es perfectamente aceptable en cuanto se hace desaparecer el infinitivo.

Y lo mismo ocurre cuando el verbo es estar:

17) A:- ...y me dijo que María estaba casada

* ¿Estar María casada?

* ¿María estar casada?

B:- ¿María casada?

¿Casada María?

Se diría que se comportan como las interrogaciones en infinitivo pero, paradójicamente, van sin infinitivo, de tal modo que resultan ser interrogaciones nominales. ¿Qué solución habrá que arbitrar para dar cuenta adecuadamente de esta situación? La respuesta a este problema pasa por la necesidad de comprender de una manera global los mecanismos que entran en funcionamiento en este tipo de construcciones y que constituyen su razón de ser: a todo ello está dedicada la próxima sección.

-Al marcharte tú, tuvimos que suspender la reunión.

-Al tú marcharte, tuvimos que suspender la reunión. 


\section{INTERPRETACIÓN}

Hasta ahora hemos examinado las caracteristicas formales más destacadas de este tipo de oraciones; ha llegado el momento de precisar cuál es el valor significativo que debe asignarse a todos estos rasgos.

Las construcciones que estamos estudiando se han puesto en relación alguna vez, de modo más o menos explícito, con ciertas estructuras repetitivas o «de eco». Hernanz Carbó ${ }^{20}$, refiriéndose a nuestros ejemplos $I) a$ y $I) b$, afirma:

«... representan pseudo-interrogativas o interrogativas "eco", que, más que para preguntar, se usan para buscar confirmación de lo que se ha dicho anteriormente. En términos de Sauer, "these are questions which are an echo of part of a 'stimulus' statement and express surprise as well as implying a negative answer.m

Vimos, efectivamente, que esto puede ser así en contextos como los ilustrados en 3), 4) y 8), y parcialmente en 5). Pero ésta no parece ser una característica necesaria para definirlas y comprender su interpretación. El diálogo 14) resulta perfectamente coherente, y, sin embargo, la interrogación general no es un eco de nada de lo dicho anteriormente:

14) A:- No puedo aguantarlo más; ya no merece la pena seguir intentándolo: voy a dimitir

B:- ¿Arredrarte tú ante las primeras dificultades? No puedo creerlo.

En este caso la interrogación con infinitivo es una réplica, pero no un «eco». Parece, por tanto, que la generalización propuesta no es válida, de modo que es necesario buscar una interpretación más satisfactoria.

La interrogación como modalidad gramatical se caracteriza, como es bien sabido, por una serie de rasgos formales (determinada entonación, presencia de palabras interrogativas...). Parece lógico dotar de un significado preciso a cada uno de estos rasgos. Pues bien, la entonación que distingue a la interrogación general tiene como sentido el de no kcerrar» el vínculo entre sujeto y predicado, el de no expresar el signo de polaridad (positiva o negativa) que los une. De este modo, la interrogación

20 Hernanz Carbó, Op. cit., p. 381. 
cuyo predicado es un verbo temporalizado "pone en tela de juicio» una afirmación concreta sobre un «momento de la realidad» concreto.

De otro lado, el infinitivo, puesto que carece de marcas de tiempo y modo, representa la «acción», el significado del verbo en cuanto tal, en sí mismo, sin referirlo a otros patrones externos, ni limitarlo a una localización temporal. Entre el infinitivo independiente y su sujeto -asignado por medios léxicos o por medios contextuales- queda establecida una relación "pura», no referida explícitamente a un hecho determinado.

De todo ello se deduce, por tanto, que una interrogación general en infinitivo, desde el punto de vista semántico, se caracteriza por no expresar el signo de polaridad correspondiente a la vinculación entre un sujeto y un contenido significativo de carácter verbal sin temporalizar.

Surge, entonces, una explicación para el fenómeno al que se refería el apartado anterior, sobre la imposibilidad de aparición del infinitivo de los verbos copulativos: si el infinitivo está desprovisto de marcas de tiempo-modo y persona-número y si los verbos copulativos funcionan, en el fondo, como nexos de unión que proporcionan un "soporte" léxico a aquellos morfemas (de manera que el núcleo del predicado no es el verbo copulativo, sino el atributo que lo acompaña), resulta lógico que la construcción que se caracteriza por prescindir de dichos morfemas elimine también su "soporte», dando lugar a una de las llamadas oraciones nominales.

Hemos convenido en que las oraciones que ahora estudiamos no llevan el patrón entonativo $/ 12212 \uparrow$ /, que es el no-marcado, sino $12232 \uparrow$ /. Más arriba ya quedó dicho que este esquema prosódico era el que se utilizaba para diferenciar de la interrogación neutra -n la que la indeterminación de la variable de polaridad positiva/negativa corresponde a un desconocimiento real por parte del emisor de cuál es el valor que debe asignarle-, a aquella otra orientada en la que no se cumple el supuesto anterior.

La entonación $12232 \uparrow /$ de las interrogaciones en infinitivo debe relacionarse con el carácter polifónico y argumentativo que el emisor confiere a los enunciados que las contienen. La noción de polifonía procede de Anscombre y Ducrot ${ }^{21}$. Un enunciado es polifónico cuando, por medio de él, el emisor está haciendo oír no su propia voz, sino la de otro interlocutor, ya sea real o supuesto 22 .

Se emplean formas también polifónicas en otra clase de interrogaciones hipotéticas en infinitivo, en las que un hablante formula una pre-

21 J. C. Anscombre y O. Ducrot, «L'argumentation dans la langue», Langages, 42 (1976), pp. 5-27.

${ }_{22}$ Sobre otros usos polifónicos de la interrogación puede verse el capítulo $12 \mathrm{de} \mathrm{mi}$ tesis: La interrogación... 
gunta real a su interlocutor, pero antes de dejarle responder avanza una hipótesis, en forma interrogativa, sobre cuáles pueden ser las palabras de aquél. Véase el siguiente ejemplo:

15) ¿Qué les hiciste? ¿Arrancarles la piel a tiras? ¿O extraerles cuidadosamente los ojos? ${ }^{23}$

El enunciado anterior es una ficción de un posible diálogo como el ejemplificado en

16) A:- ¿Qué les hiciste?

B:- Arrancarles la piel a tiras

Extraerles cuidadosamente los ojos

La distribución de este tipo de construcciones es diferente, ya que no son réplicas al enunciado de un emisor precedente. El infinitivo queda, entonces, ligado al verbo anterior del mismo modo en que lo están respuesta y pregunta, manteniéndose en estos casos el régimen preposicional exigido por el verbo

17) ¿En qué estás pensando? ¿En decírselo?

Probablemente ésta es la razón que justifica el hecho de que tales oraciones no admitan siempre la presencia de un sujeto especificado, sino sólo cuando lo permita el verbo principal: 17) sí puede llevarlo cuando ambos son correferenciales

18) - A:- ¿En qué estás pensando? ¿En decírselo tú?

B:- ${ }^{*}$ ¿En qué estás pensando? ¿En decírselo él?

No lo admite, en cambio, 15), como demuestra la agramaticalidad de

${ }^{23}$ El ejemplo es de Sastre citado por Skydsgaard, Op. cit., p. 1.130. 
19) ¿Qué les hiciste? ¿Arrancarles tú la piel a tiras?

¿O extraerles tú cuidadosamente los ojos?

La interrogación ejemplificada en 15) y 17) no debe, pues, confundirse con las que estamos aquí analizando.

Gracias a la noción de polifonía se comprende mejor la relación existente entre la interrogación-réplica en infinitivo y las estructuras «de ecom: en muchas ocasiones el emisor de la interrogación efectivamente vuelve a hacer oír algunas de las palabras que su interlocutor acaba de pronunciar

20) - Aquí todos, no se enfade

- ¿Enfadarme? ¡Quiá! (Casona)

21) - Le tienes envidia y quieres vengarte...

- ¿Vengarme, de qué? (Miró)

22) - Tendrá que volverse

— ¿Volverse él? Usted no sabe quién es Pipo (Casona) ${ }^{24}$

Pero, según ponía de manifiesto el diálogo 14), no es necesario que haya una repetición de palabras precedentes, sino que es suficiente con que el contenido que aparece en la interrogación pueda ser atribuible al primer emisor en virtud de los principios de encadenamiento lógico y de coherencia. Skydsgaard no recoge ejemplos de este uso, pero su existencia parece innegable

23) A:- Dejémosles en paz

B:- ¿Y ceder a sus presiones? Ni soñarlo

La réplica de $B$ es consecuencia lógica o inferencia de lo dicho por $A$; de modo que $B$ no está hablando por sí mismo, sino poniendo de relieve lo que podrían haber sido palabras de $A$. Queda, así, demostrado el carácter polifónico de esta clase de enunciados.

24 Los ejemplos están nuevamente tomados de Skydsgaard: Op. cit., pp. 1.134-35. 
La noción de argumentación procede también de Anscombre y Ducrot $^{25}$. Según dichos autores, la presentación de un contenido proposicional en forma interrogativa adquiere un valor argumentativo opuesto al del signo de su polaridad. De este modo, 24)a va en la dirección argumentativa de 24) $b$-que presenta el signo de polaridad inverso-, y no en la de 24)c

24) a - Vayamos a este cine: la película es mejor, y, además, ¿no está más cerca?

b - Vayamos a este cine: la película es mejor, y, además está más cerca

c - \# Vayamos a este cine: la película es mejor, y, además, no está más cerca

De este modo, podemos explicar por qué las réplicas interrogativas en infinitivo parecen conducir a una respuesta negativa, como decía Sauer; 0

«... implican una negativa vehemente ante la creencia de que ha de realizarse algo desagradable» 26 .

Es su carácter argumentativo el que hace que estas construcciones sirvan para rechazar las palabras (reales o supuestas) del interlocutor. Así lo ponen, además, de manifiesto los comentarios que normalmente se añaden a las interrogaciones en infinitivo: Ni hablar, Ni soñarlo, Quiá!, En absoluto... Y sólo funcionan de esta manera las interrogaciones que distribucionalmente figuran como réplicas de diálogo ${ }^{27}$.

\footnotetext{
25 Véase Anscombre y Ducrot, «Art. cit.m; e «Interrogation et argumentation», Langue Française, 52 (1981), pp. 5-21. En ambos trabajos hay explicaciones detalladas y muchos ejemplos.

26 Son palabras de J. A. Pérez Rioja, Gramática de la Lengua Española, Madrid, Tecnos, 1954 (p. 432).

27 En efecto, es imposible la inversión argumentativa en ejemplos como 15 ), porque no aparecen en el mismo tipo de situación discursiva. El carácter argumentativo puede, por supuesto, cancelarse: mientras que en el primer ejemplo el comentario añadido sigue la dirección de la expectativa, en el segundo la rompe, produciendo un efecto retórico bien distinto:

A:-... Espero que no te moleste...

B:- ¿Molestarme? Por supuesto que no, en absoluto

A:-... Espero que no te moleste

B:- ¿Molestarme? Por supuesto que sí me molesta
} 


\section{CONCLUSIÓN}

He analizado las propiedades formales y el valor significativo de una clase particular de interrogación general directa en infinitivo, usada como réplica de diálogo. Como resumen de lo dicho, y a modo de conclusión, he aquí las notas más destacables.

Desde el punto de vista gramatical estas oraciones quedan caracterizadas por los siguientes rasgos:

- distribucionalmente constituyen siempre réplicas a un enunciado previo de otro emisor; no pueden, por tanto, ser iniciadoras de diálogo;

- llevan entonación «marcada» $/ 2232 \uparrow /$;

- admiten libremente la aparición del sujeto del infinitivo; y

- su elemento central es el núcleo del predicado, esto es, el infinitivo, cuando el predicado es verbal; si el predicado es nominal, el núcleo es el atributo, por lo que el infinitivo ha de ser automáticamente eliminado, constituyéndose de este modo una oración interrogativa nominal.

En cuanto a la interpretación, dos son las características más significativas:

- La entonación es marca de interrogación orientada, y, en particular, de interrogación polifónica: por medio de ella el emisor hace oír palabras reales o supuestas de su interlocutor; y

- esta interrogación, por su entonación y su distribución en el discurso, adquiere un carácter argumentativo: se usa para apoyar la proposición de signo opuesto al que presenta la fórmula interrogativa. 